\title{
SHORELINE CHANGE THREAT TO COASTAL ZONE: A CASE STUDY OF
}

\author{
KARWAR COAST \\ Arunkumar Yadav ${ }^{1 *}$, Basavanad .M. Dodamani ${ }^{1}$ and G.S. Dwarakish ${ }^{1}$ \\ ${ }^{I}$ Department of Applied Mechanics and Hydraulics, National Institute of Technology Karnataka, Surathkal, \\ Mangaluru, India
}

\begin{abstract}
Shoreline is a triple interface of air, water and land and also the wet and dry boundary between land and sea. It is key geo-indicator of coastal environmental resource threats within the coastal zone. Shoreline change leads to causes for change in natural habitats, infrastructure change in the coastal zone and so on. These changes which rise to serious issues those are related to the coastal zone. The present study is carried out for the Karwar Coast, West Coast of India, using remote sensing and GIS Techniques. LANDSAT-8 remote sensing data which is available from 2013, coupled with GIS techniques used for the shoreline analysis. The acquired image was subjected to layer stacking to remove errors from raw image data using ERDAS IMAGINE 2014 tool and analyzed by ArcGIS 10.3 tool. For extraction of shoreline the High-Water Line (HWL) considered and visual interpretation of satellite imageries has been carried out to segregate the HWL, in addition to this to collect the ground truth data, the shoreline track is carried out using Trimble GPS (Global Positioning System) device. Digital Shoreline Analysis System (DSAS) were used to find rates of change of shoreline such as End Point Rate (EPR), Net Shoreline Movement (NSM). Results were concentrated on EPR as the analysis was carried for every two years from 2013 to 2017 of postmonsoon period to find out erosion and accretion. It is found to be Tagore beach is changed from accretion zone to erosion zone, and Devbagh beach is experiencing erosion. The study finds that the shoreline change is threatening to Karwar coastal zone.
\end{abstract}

Keywords: Shoreline, HWL, EPR, NSM

\section{Introduction}

Shoreline position changes have become, in recent years, one of the major environmental problems affecting the coastal zones worldwide. Indeed, nearly $80 \%$ of the world's coasts are eroding, with rates ranging from 1 $\mathrm{cm} /$ year to $10 \mathrm{~m} /$ year (Pilkey and Hume, 2001). The shoreline changes analysis has been subjecting of several studies worldwide (Zuzek et al., 2003, Maiti and Bhattacharya, 2009; Appeaning Addo et al., 2011). Shoreline changes are related to natural processes (wave, current, nature of coastal landforms) and anthropogenic interventions (sand mining, wild urbanization, tourism, construction of coastal infrastructure)(Carter,1988; Komar,1989; Scott, 2005; Guariglia et al., 2006; Manca et al., 2013; Natesan et al., 2015). Shoreline change, as one of the most frequent natural hazards and the most widely researched coastal issues in the world, poses a serious threat to the coastal environment, human life, and property (Bagli and Soille, 2003). It potentially generates more severe impact on the environment and human life especially due to the complexity and dynamics of environmental and social processes in an area. Therefore, shoreline change analysis has a significant role in coastal protection planning and risk and disaster management, e.g., through numerical method calibration and verification, sea-level rise assessment, and hazard zone development, as well as the policy-making process of coastal area development (Mutaqin, 2017).

Remote sensing, as compared to conventional survey techniques, is applicable for monitoring shoreline change in the coastal area effectively, because of its high accuracy, more efficiency, and cost-effectiveness (Boak and Turner, 2005). Meanwhile, Geographic Information Systems (GIS) technology enables users to create high-quality maps as well as visualize and simplify large and complex data. Research from various disciplines has been applying remote sensing data and GIS technology in coastal studies (Yang et al., 2004). 
The water/landline has used in micro-tidal zones; the dry/wet sand line has been used in the macro-tidal area (Pardo-Pascual et al., 2018).

The present study aims to analyze the shoreline change using, an Arc GIS extension tool Digital Shoreline Analysis System (DSAS) and Landsat 8 for the period of 2013 to 2017 post monsoon in addition to acquired GPS data of May and October month 2017. Several statistical approaches have used for determining the rates of shoreline changes, including End Point Rates (EPR) and Net Shoreline Movement (NSM) to map and quantify the erosion and accretion areas and to evaluate the long-term rates of shoreline changes along the Karwar coast.

\section{Study Area and Data Products}

Karwar coast has two beaches namely; Devbagh beach in the North and Ravindranath Tagore beach in the south which is separated by Kali river estuary, along the West Coast of India is the study area. The study area lies between $14^{\circ} 48^{\prime} 00^{\prime \prime}-14^{\circ} 52^{\prime} 30^{\prime \prime}$ North latitude and $74^{\circ} 06^{\prime} 00^{\prime \prime}-74^{\circ} 08^{\prime} 00^{\prime \prime}$ East longitude as shown in Figure 1. The coast bordered by the Arabian Sea on the west and the Western Ghats in the east. The coast exposed to the seasonally reversing monsoon winds, average rainfall per year is $4209 \mathrm{~mm}$. Of the total rainfall, $80 \%$ is from June to August. The temperature ranges from $21^{\circ} \mathrm{C}$ in December to $36^{\circ} \mathrm{C}$ in April (Hegde and Akshaya, 2015). The tides in the study area are mixed semidiurnal, the range of which raises towards the north of the state (Kumar and Jayappa, 2009). Significant wave height up to $6 \mathrm{~m}$ have been recorded during the monsoon along the west coast of India (Kumar et al., 2006) and is normally less than $1.5 \mathrm{~m}$ during rest of the period. Geometrically corrected and orthorectified Landsat-8 satellite data for post monsoon from 2013 to 2017 remotely sensed satellite dataset had used for shoreline analysis studies of Devbagh and Ravindranath Tagore beach shown in Table 1.

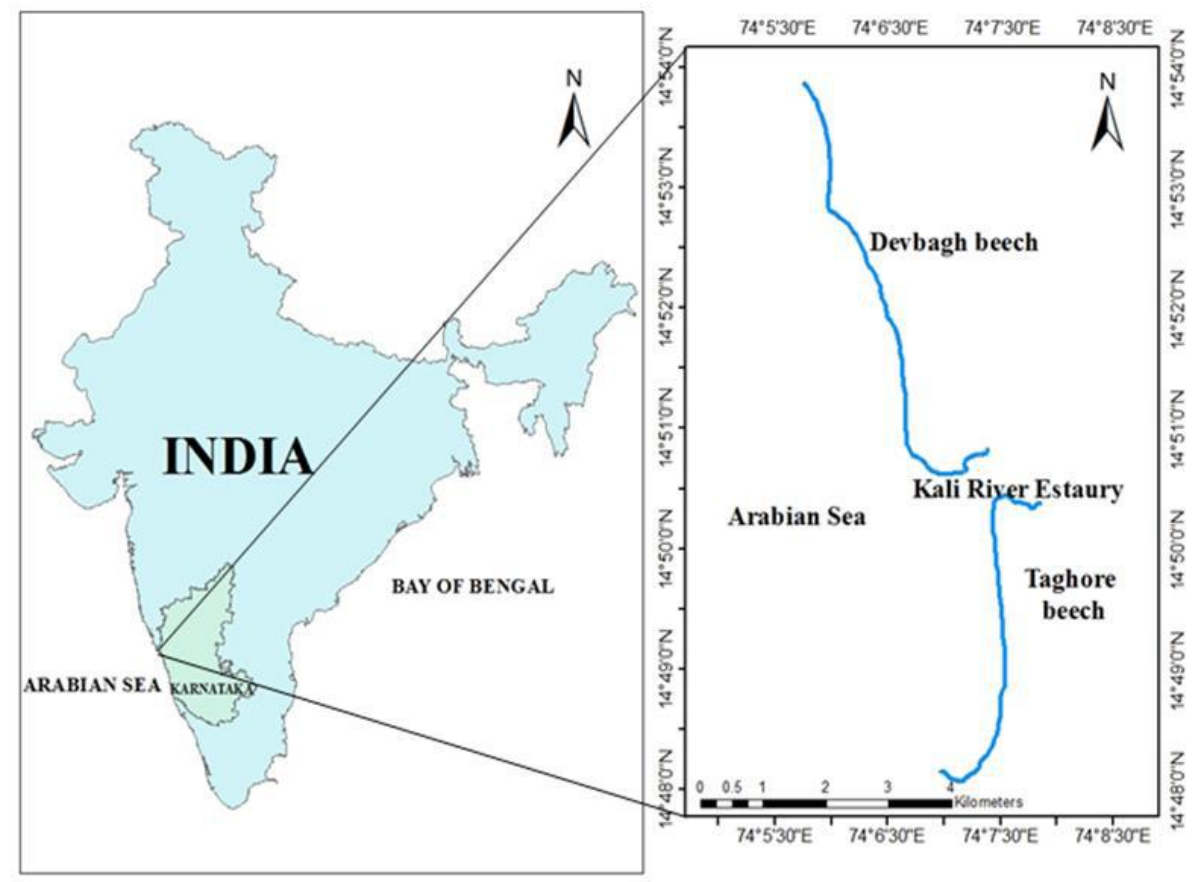

Figure 1: Study Area 
Table 1, Specifications of satellite data used for shoreline change study

\begin{tabular}{lllll}
\hline S1 No. & Satellite \& Sensor & Acquired Date & Path/Row & Resolution (m) \\
\hline 01 & Landsat-8 OLI/TIRS & $20 / 10 / 2013$ & $146 / 50$ & 30 \\
\hline 02 & Landsat-8 OLI/TIRS & $23 / 10 / 2014$ & $146 / 50$ & 30 \\
\hline 03 & Landsat-8 OLI/TIRS & $26 / 10 / 2015$ & $146 / 50$ & 30 \\
\hline 04 & Landsat-8 OLI/TIRS & $28 / 10 / 2016$ & $146 / 50$ & 30 \\
\hline 05 & Landsat-8 OLI/TIRS & $31 / 10 / 2017$ & $146 / 50$ & 30 \\
\hline S1 No. & GPS & Acquired Date & Resolution (m) \\
\hline 06 & Trimble GPS & $28 / 05 / 2017$ & 2.6 & \\
\hline 07 & Trimble GPS & $19 / 10 / 2017$ & 2.6 & \\
\hline
\end{tabular}

The above datasets were projected to World Geodetic System (WGS) 1984 Northern hemisphere $43^{\circ} \mathrm{N}$ datum Universal Transverse Mercator (UTM) projection. GPS datasets were carried out differential correction using the Indian Institute of Science as a base.

\section{Method}

\begin{tabular}{|l|l|}
\hline Multi date Landsat-8 data from USGS & Generation of Baseline of 250m \\
Layer Stack using ERDAS Imagine & Comeration of Transects by DSAS tool \\
Band 5,6 and 7 of Landsat 8 for FCC & Shoreline change rate data \\
Digitization of shoreline of the study area & \\
Using Arc GIS (10.3 & \\
Adding GPS acquired shoreline Data &
\end{tabular}

Figure 2: Shoreline extraction and computation of rates.

Shoreline analysis was carried out for five years (2013 to 2017). The Ortho-rectified satellite images of the study area from the sensors Landsat-8, Operational Land Imager (OLI) and Thermal Infrared Sensor (TIRS) downloaded from USGS Earth Explorer web tool. The additional information about the specifications of the satellite data used in the study given in Table 1 . The tidal range along the study region is about $1.5 \mathrm{~m}$ and the submergence of the land associated with high tide period is less than 5-6 m (Hegde and Akshaya, 2015). Hence no additional corrections are undertaken for the delineation of shoreline other than approximately common acquisition time and period of the year. The satellite images downloaded by considering image retrieval date. The images have to retrieved in the days of the same season to anticipate tidal variation error between the images during the shoreline extraction process.

\section{Shoreline changes analysis}

Shoreline change is analyzed statistically using DSAS extension in ArcGIS tool. DSAS has many statistical options for analyzing shoreline change data. These options are, for example, Shoreline Change Envelope (SCE), Net Shoreline Movement (NSM), End Point Rate (EPR), and Linear Regression (LRR) (Thieler, et al., 2009). NSM provides a shoreline distance at each transect; however, its results do not include information on 
the rate at which the shoreline changes. NSM represents a total distance between the oldest and the most recent shoreline, i.e., 2013 and 2017, respectively.

At present study, EPR and NSM were calculated for every year 2013-2014, 2014-2015, 2015-2016 and 2016 2017 respectively. GPS data collected from May and October 2017. The baseline should be establish adjacent to the series of shoreline positions, were established at $250 \mathrm{~m}$ on onshore due to the consideration of coastal zone.

\section{Result and Discussion}

The interpretation of the results of the multi-temporal satellite imagery shows that the shoreline change in Karwar coastal area is dynamic. As one of the most dynamic processes in coastal areas, shoreline change may occur as a short-term event caused by hydrodynamic factors or a long-term event like tectonic activities (Marfai et al., 2008 and Mills et al., 2005)

\section{Shoreline change rate}

EPR is carried out for both Karwar coast namely Devbagh beach and Tagore beach, for the years 2013-2014, 2014-2015, 2015-2016, 2016-2017 and 2017 May and October GPS shoreline track.

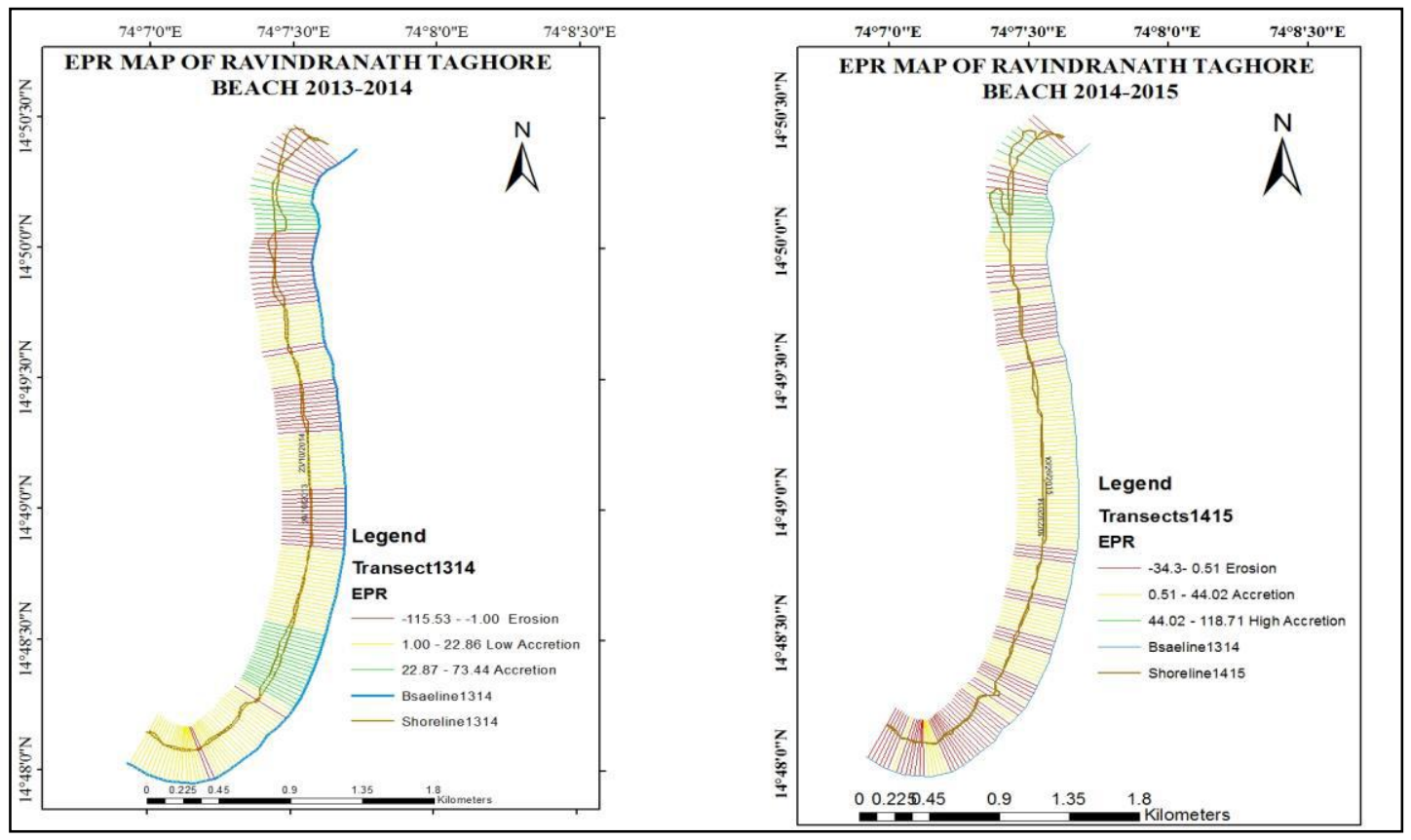

Figure 3: Shows EPR map Tagore beach for a particular year

From figure 3, Tagore beach during the post-monsoon season with average rainfall 2916.5mm for years 201314 , at transect 3 has maximum shoreline erosion of $-115.53 \mathrm{~m} / \mathrm{yr}$ (EPR), and $116.48 \mathrm{~m}$ (NSM) observed. At transect 19 has maximum shoreline Accretion of $73.44 \mathrm{~m} / \mathrm{yr}$ (EPR) and $74.04 \mathrm{~m}$ (NSM). Average accretion rate is $3.56 \mathrm{~m} / \mathrm{yr}$ (EPR) and $0.11 \mathrm{~m}$ (NSM). Similarly for the years 2014-15 with average rainfall $2946.41 \mathrm{~mm}$ at transect 15 maximum shoreline accretion of $118.71 \mathrm{~m} / \mathrm{yr}$ (EPR) and $119.69 \mathrm{~m}$ (NSM) Transect 12 maximum shoreline erosion of $-34.33 \mathrm{~m} / \mathrm{yr}$ (EPR) and $-34.61 \mathrm{~m}(\mathrm{NSM})$. Average accretion rate is $9.00 \mathrm{~m} / \mathrm{yr}$ (EPR) and $0.29 \mathrm{~m}(\mathrm{NSM})$.

From figure 4, Tagore beach during post-monsoon with average rainfall $2811.27 \mathrm{~mm}$ for years $2015-16$, at transect 15 has maximum shoreline erosion of $-88.85 \mathrm{~m} / \mathrm{yr}(\mathrm{EPR})$ and $-89.58 \mathrm{~m}(\mathrm{NSM})$ observed. At transect 
2 has maximum shoreline Accretion of $124.24 \mathrm{~m} / \mathrm{yr}(\mathrm{EPR})$ and $125.56 \mathrm{~m}$ (NSM). Average accretion rate is $4.21 \mathrm{~m} / \mathrm{yr}(\mathrm{EPR})$ and $0.13 \mathrm{~m}$ (NSM). During post-monsoon of 2016-2017 (with no rainfall data) at transect 16 maximum shoreline accretion of $72.13 \mathrm{~m} / \mathrm{yr}(\mathrm{EPR})$ and $72.52 \mathrm{~m}(\mathrm{NSM})$ is observed. Transect 4 has maximum shoreline erosion of $-71.91 \mathrm{~m} / \mathrm{yr}(\mathrm{EPR})$ and $-72.3 \mathrm{~m}(\mathrm{NSM})$. The average erosion rate is $-6.49 \mathrm{~m} / \mathrm{yr}(\mathrm{EPR})$ and $-0.21 \mathrm{~m}(\mathrm{NSM})$.

NSM graph of Tagore beach is as shown in figure 5 and 6. It is evident from figure 5 and six that, for year's 2013-2014 and 2015-2016 shoreline change rates are found to be approximately similar.

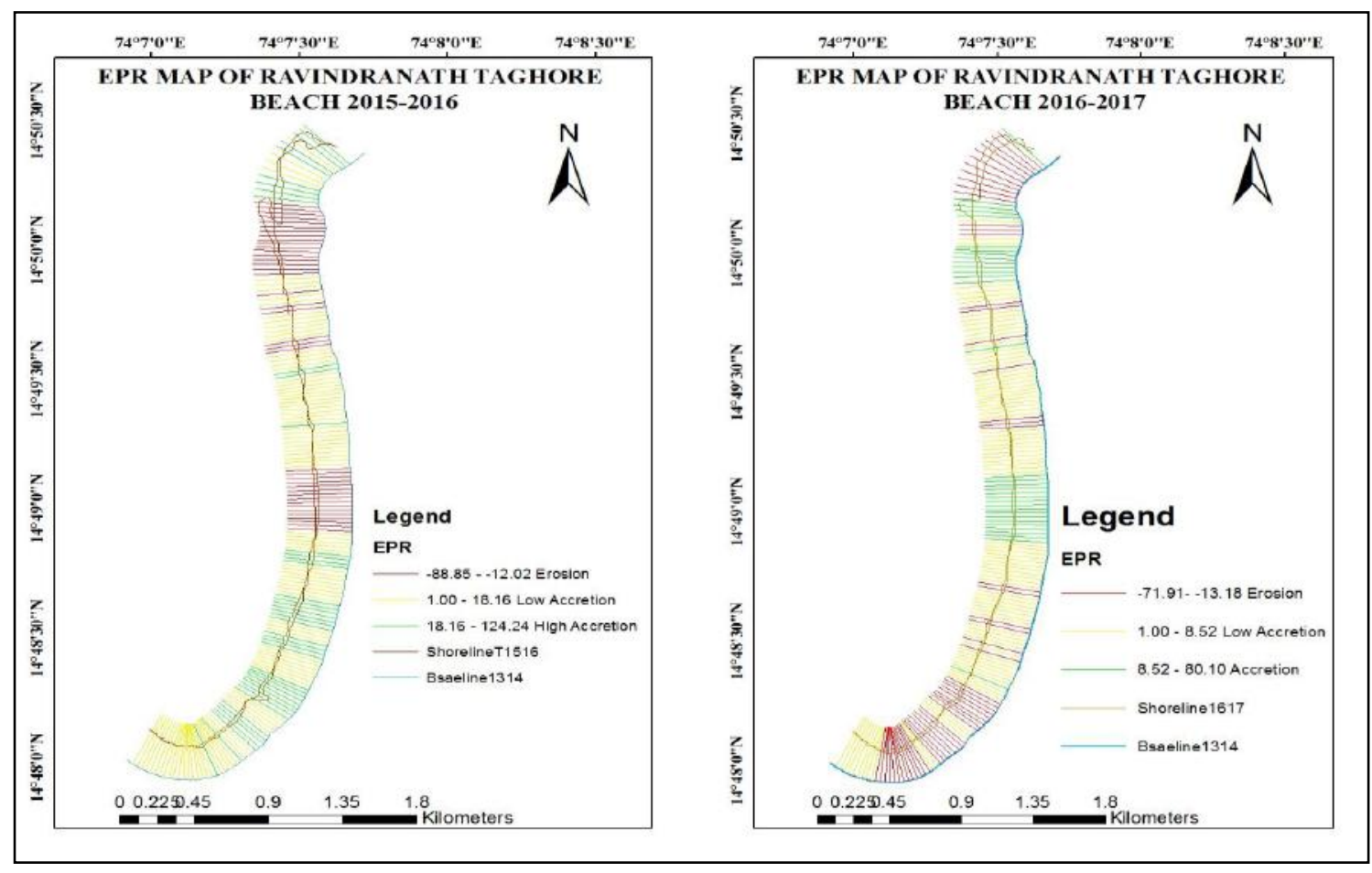

Figure 4: Shows EPR map Tagore beach for a particular year

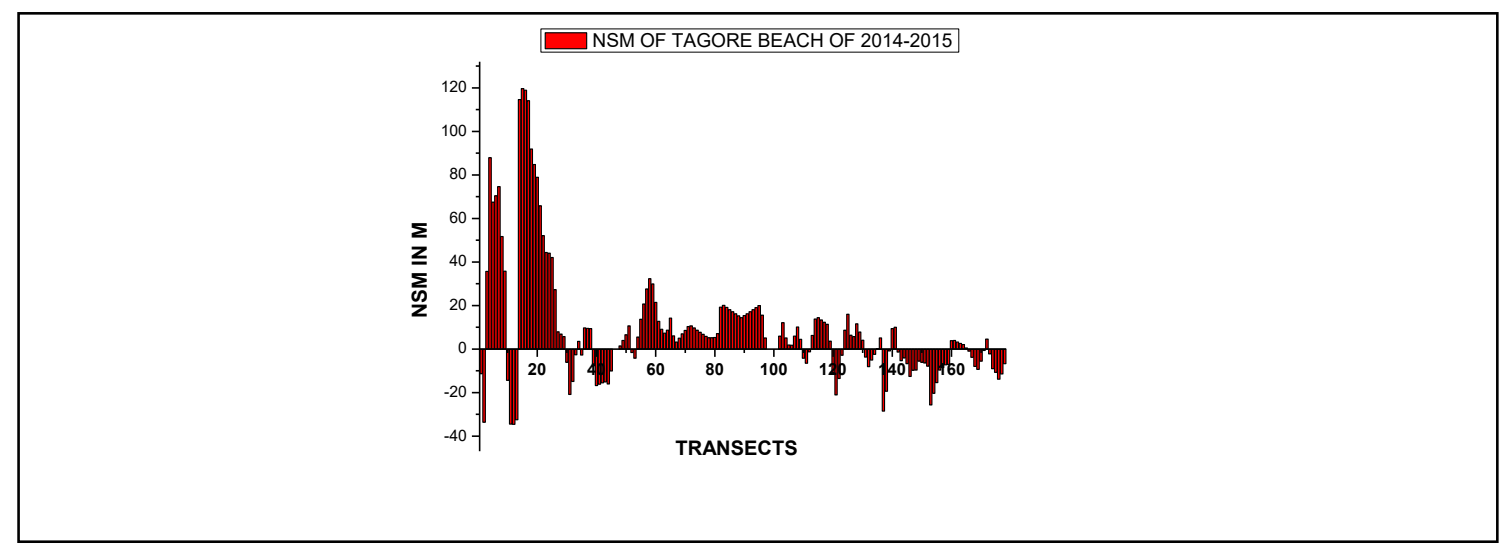

Figure 5: Shows the NSM of Tagore beach for a particular year 


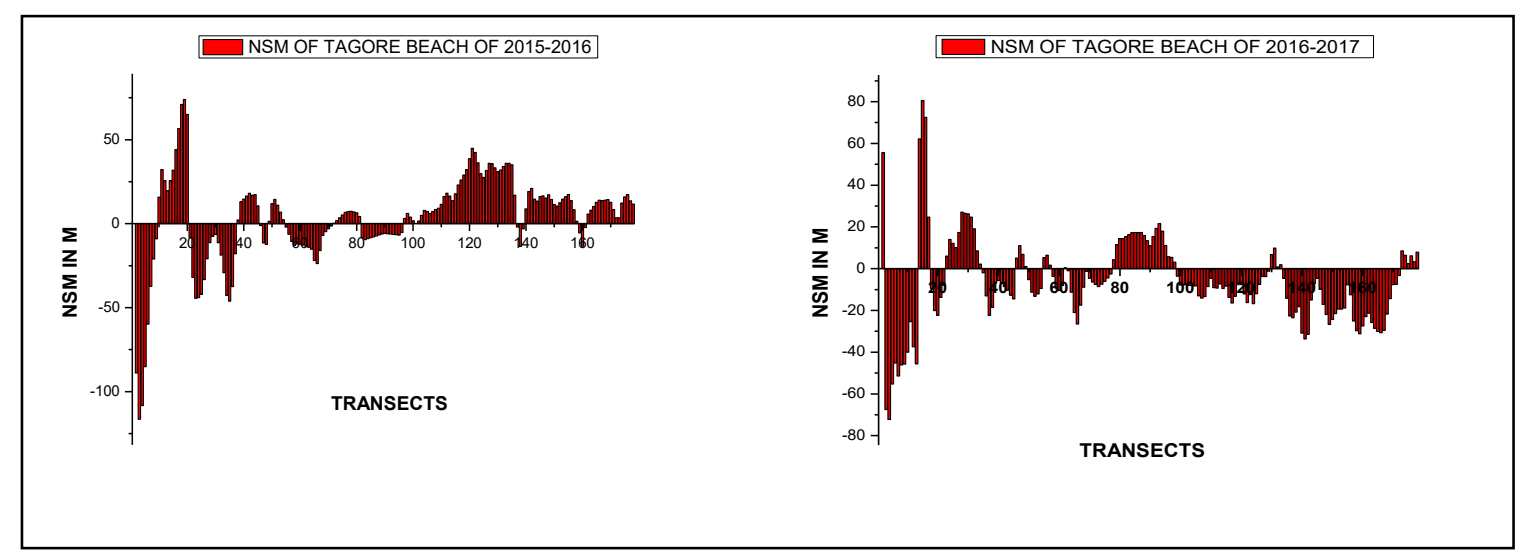

Figure 6: Shows the NSM of Tagore beach for a particular year

During post-monsoon season received with average rainfall $2916.5 \mathrm{~mm}$ for years $2013-14$. In the case of Devbagh beach, at transect 75 maximum shoreline erosion of $-44.43 \mathrm{~m} / \mathrm{yr}$ (EPR) and $-44.79 \mathrm{~m}$ (NSM) is observed. At transect 69 has maximum shoreline Accretion of $41.57 \mathrm{~m} / \mathrm{yr}$ (EPR) and $41.91 \mathrm{~m}$ (NSM). Average rate is $-5.31 \mathrm{~m} / \mathrm{yr}$ (EPR) and $0.13 \mathrm{~m}$ (NSM). Similarly for the years 2014-15 with average rainfall $2946.41 \mathrm{~mm}$ at transect 78 maximum shoreline accretion of $34.39 \mathrm{~m} / \mathrm{yr}$ (EPR) and $34.67 \mathrm{~m}$ (NSM) Transect 68 maximum shoreline erosion of $-41.03 \mathrm{~m} / \mathrm{yr}(\mathrm{EPR})$ and $-41.37 \mathrm{~m}(\mathrm{NSM})$. Average rate is $-2.07 \mathrm{~m} / \mathrm{yr}$ (EPR) and $0.05 \mathrm{~m}(\mathrm{NSM})$.

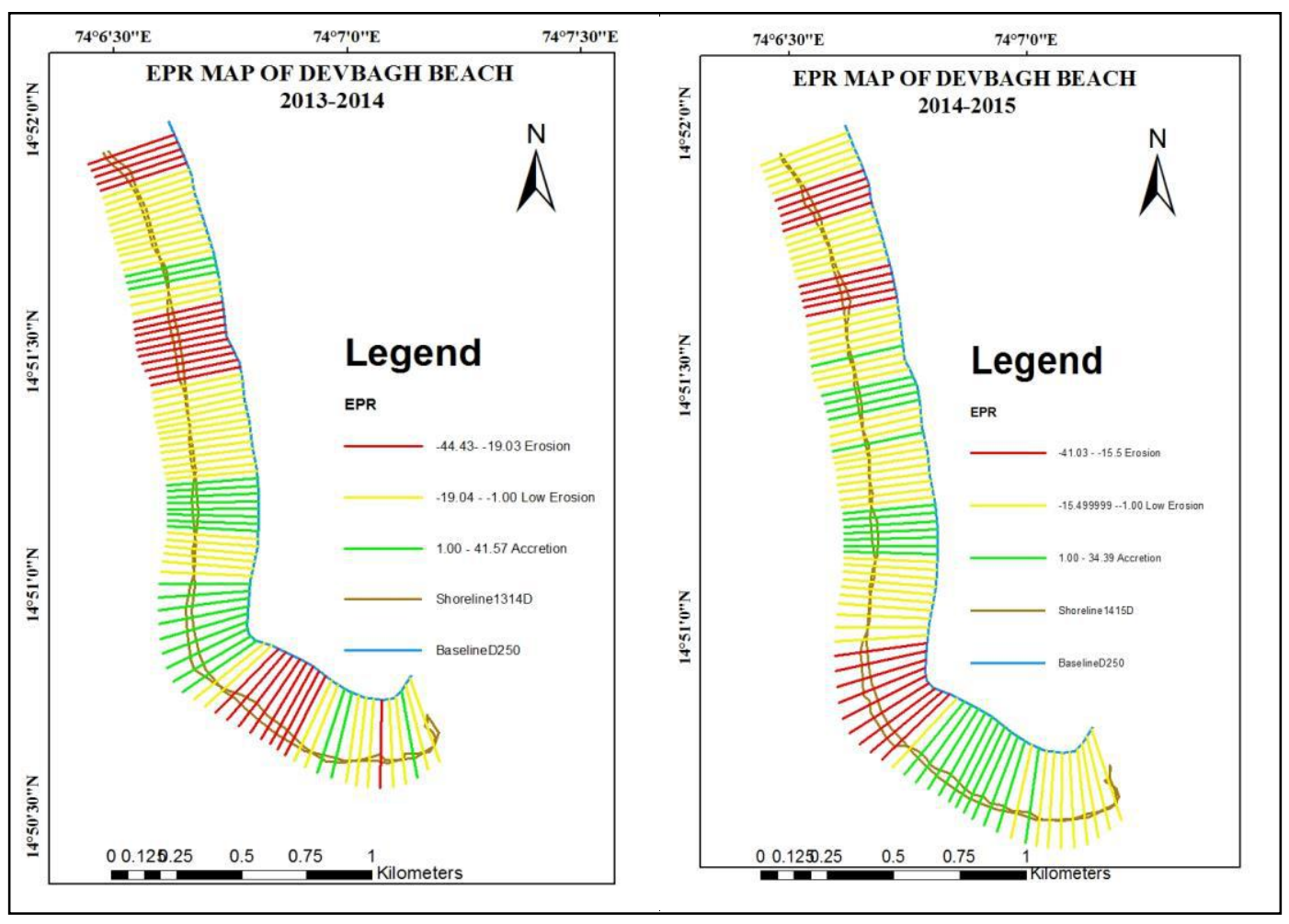

Figure 7: Shows EPR map Tagore beach for a particular year

During post-monsoon with average rainfall $2811.27 \mathrm{~mm}$ for years $2015-16$, at transect 70 has maximum shoreline erosion of $-149.69 \mathrm{~m} / \mathrm{yr}(\mathrm{EPR})$ and $-150.92 \mathrm{~m}$ (NSM) observed. At transect 81 has maximum 
shoreline Accretion of $30.93 \mathrm{~m} / \mathrm{yr}$ (EPR) and $31.18 \mathrm{~m}$ (NSM). Average rate is $-21.71 \mathrm{~m} / \mathrm{yr}(\mathrm{EPR})$ and $0.57 \mathrm{~m}$ (NSM). During post-monsoon of 2016-2017 with (No rainfall data) at transect 71 maximum shoreline accretion of $48.33 \mathrm{~m} / \mathrm{yr}(\mathrm{EPR})$ and $48.59 \mathrm{~m}(\mathrm{NSM})$ is observed. Transect 17 has maximum shoreline erosion of $-52.08 \mathrm{~m} / \mathrm{yr}(\mathrm{EPR})$ and $-52.37 \mathrm{~m}$ (NSM). Average rate is $-14.94 \mathrm{~m} / \mathrm{yr}(\mathrm{EPR})$ and $0.39 \mathrm{~m}(\mathrm{NSM})$.

To carry out ground truth observation for both the beaches, using Global position system (GPS) shoreline track was carried out for May and October of 2017. From figure 9, in case of Devbagh beach transects from 6-13, 20-30 and 75-90 found to be erosion. Transects from 31-50 found to be medium erosion and transects from 51-74 found to be high accretion. Similarly for Tagore beach transects from 24-95 medium erosion.

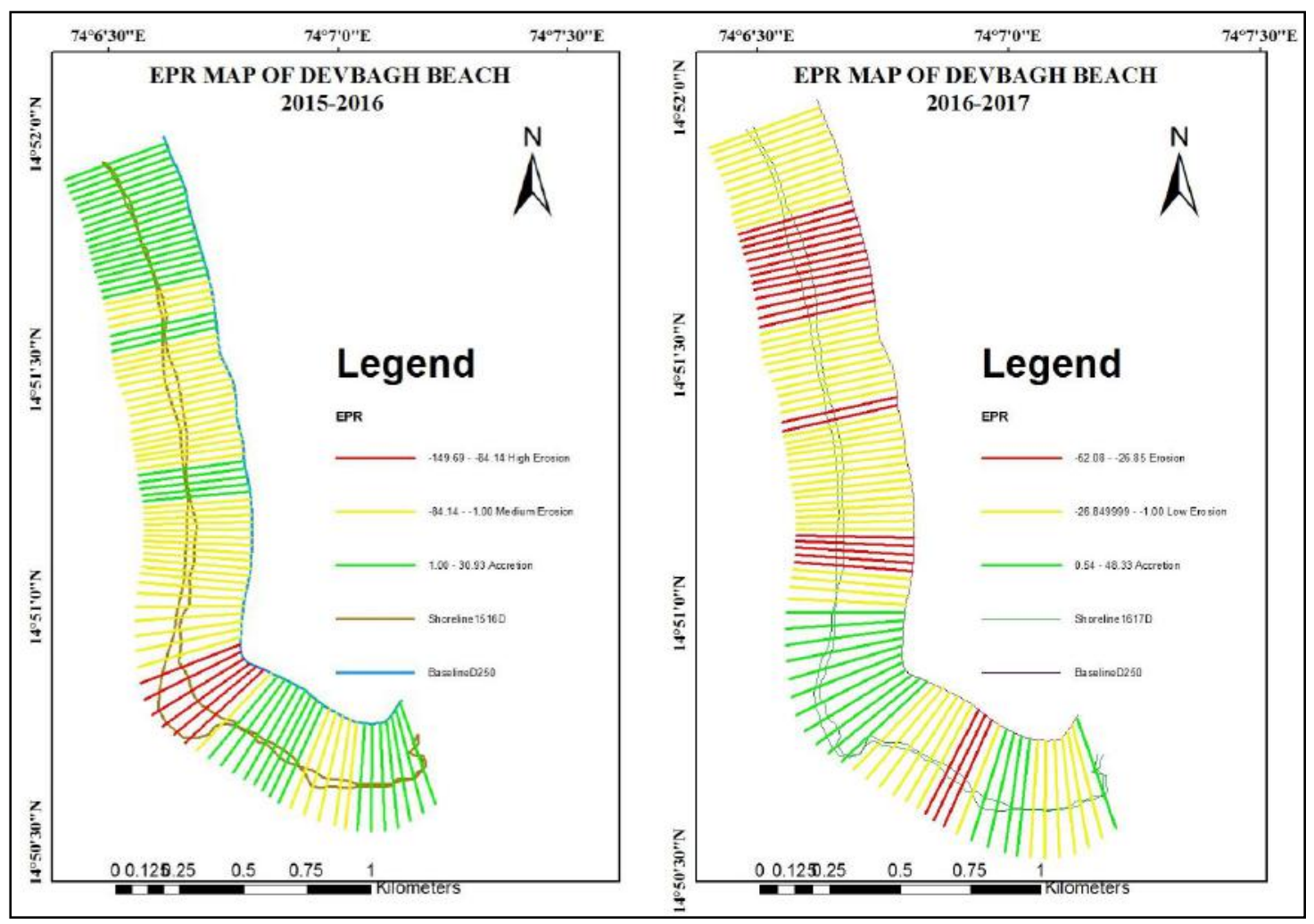

Figure 8, Shows EPR map Devbagh beach for a particular year 


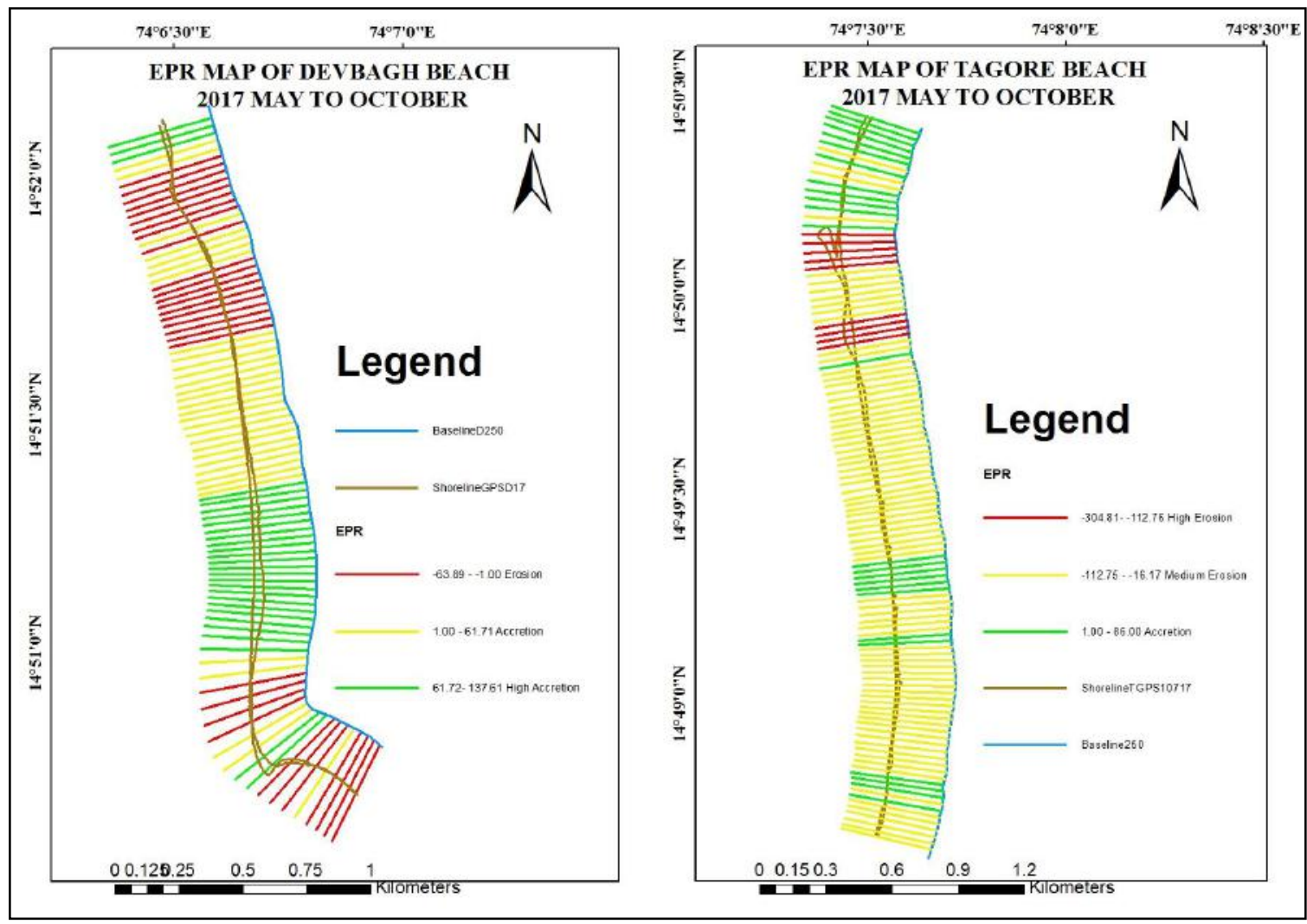

Figure 9, Shows EPR map Devbagh and Tagore beach computed by using GPS shoreline Track

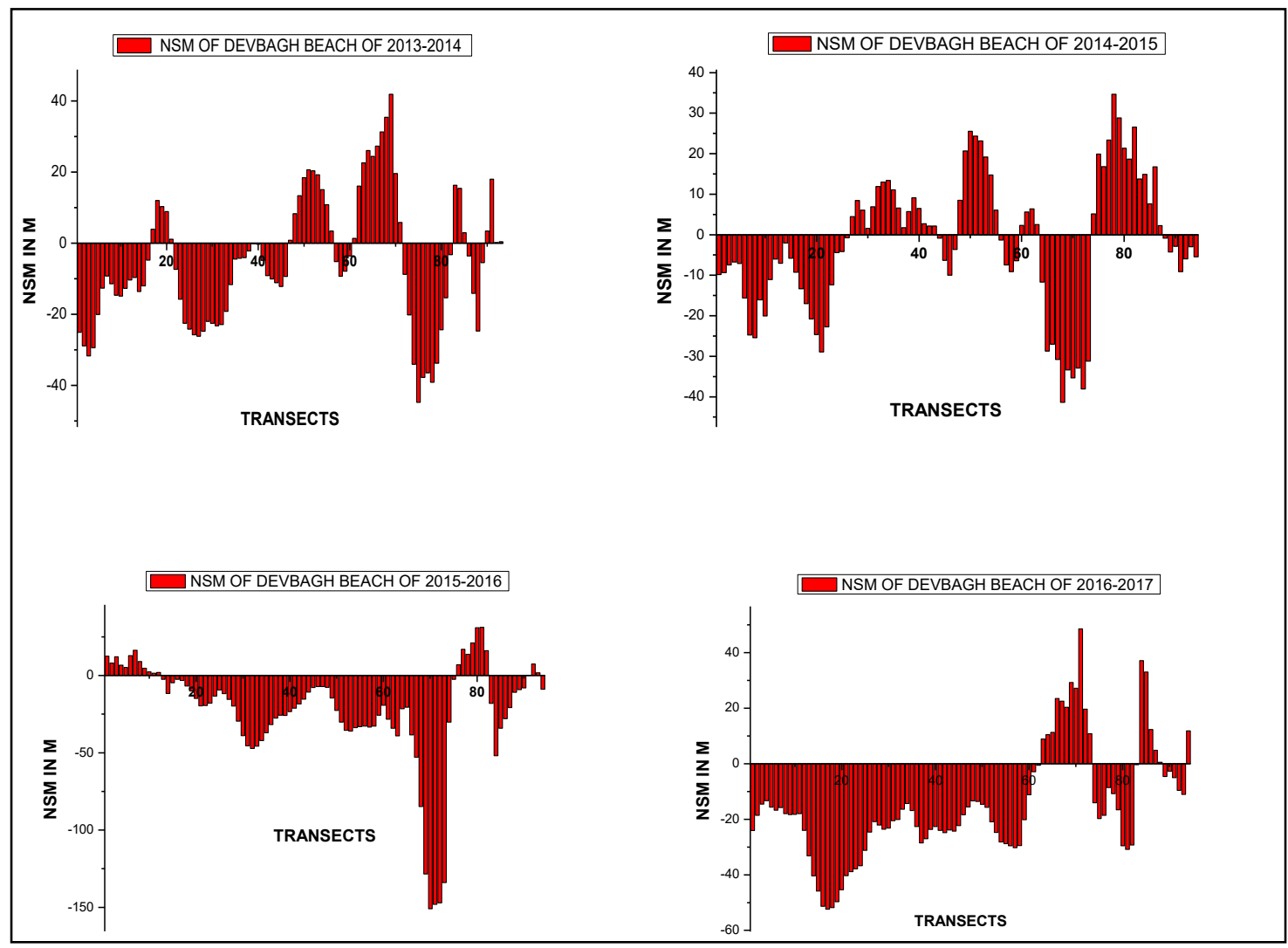

Figure 10, Shows the NSM of Devbagh beach for a particular year 


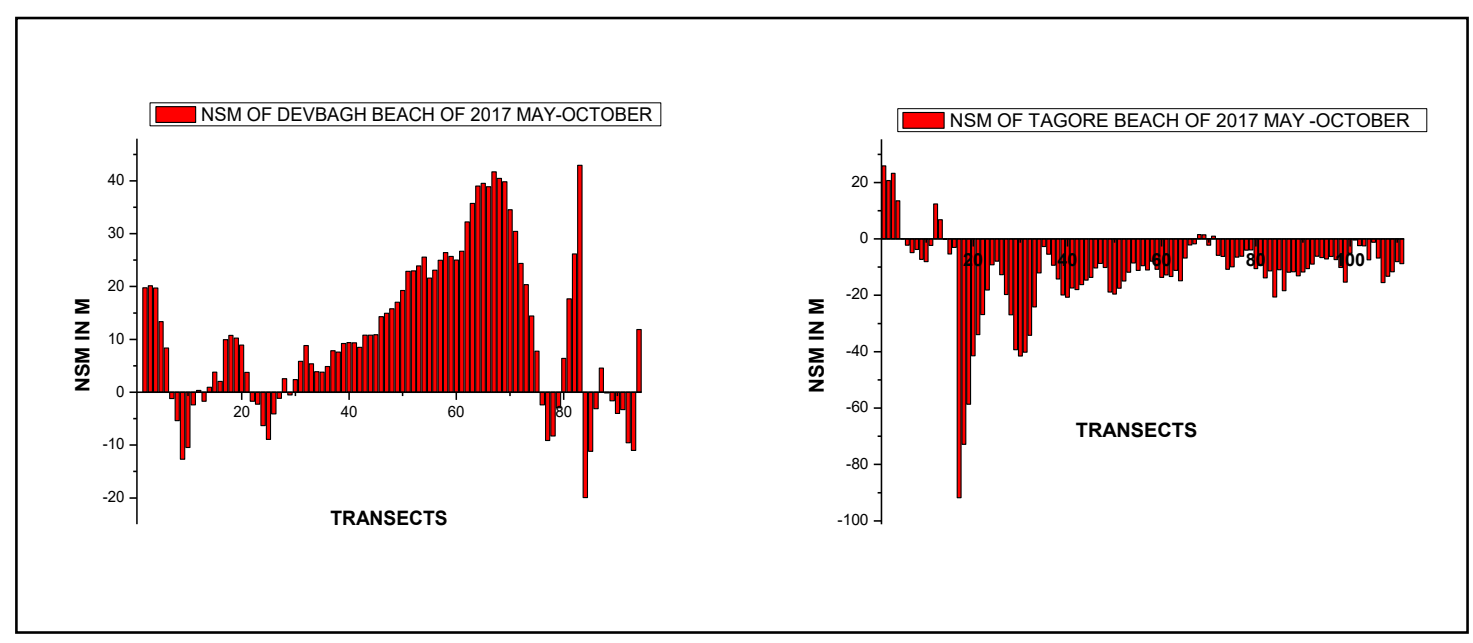

Figure 11: Shows the NSM of Devbagh and Tagore beach for 2017 using GPS shoreline track

Devbagh and Tagore beaches are separated by Kali River estuary, from figure 9 EPR and NSM it's evident that the rainfall is also responsible for shoreline change. In addition to this north side of Kali River where the Devbagh beach exists experiences average accretion of $35.78 \mathrm{~m} / \mathrm{yr}$ and NSM of $0.28 \mathrm{~m}$. Towards south side where Tagore beach situated experiences average erosion of $-3.90 \mathrm{~m} / \mathrm{yr}$ and NSM of $-0.29 \mathrm{~m}$.

From the results, it is evident that, as the rainfall maximum, beach finds to be maximum erosion and dynamic variation, especially at the estuary region. The shoreline is approaching seawall during rainfall season in case of both the beaches. This rainfall variation and climate change impact like temperature increase leads to sea level rise, may leading to shoreline change, beach variation. These changes may threaten to Devbagh beach and Tagore beach of Karwar coast. From figure 13, it shows how the rate of change of EPR is changed from accretion to erosion zone by year wise. Particularly, erosion is zone converted from 2015-16 to 2016-17. In case of Devbagh beach, it is always in erosion state. Figure 14 shows that during 2014-15 experienced less erosion comparatively but during 2015-16 and 2016-2017 have experienced high erosion.

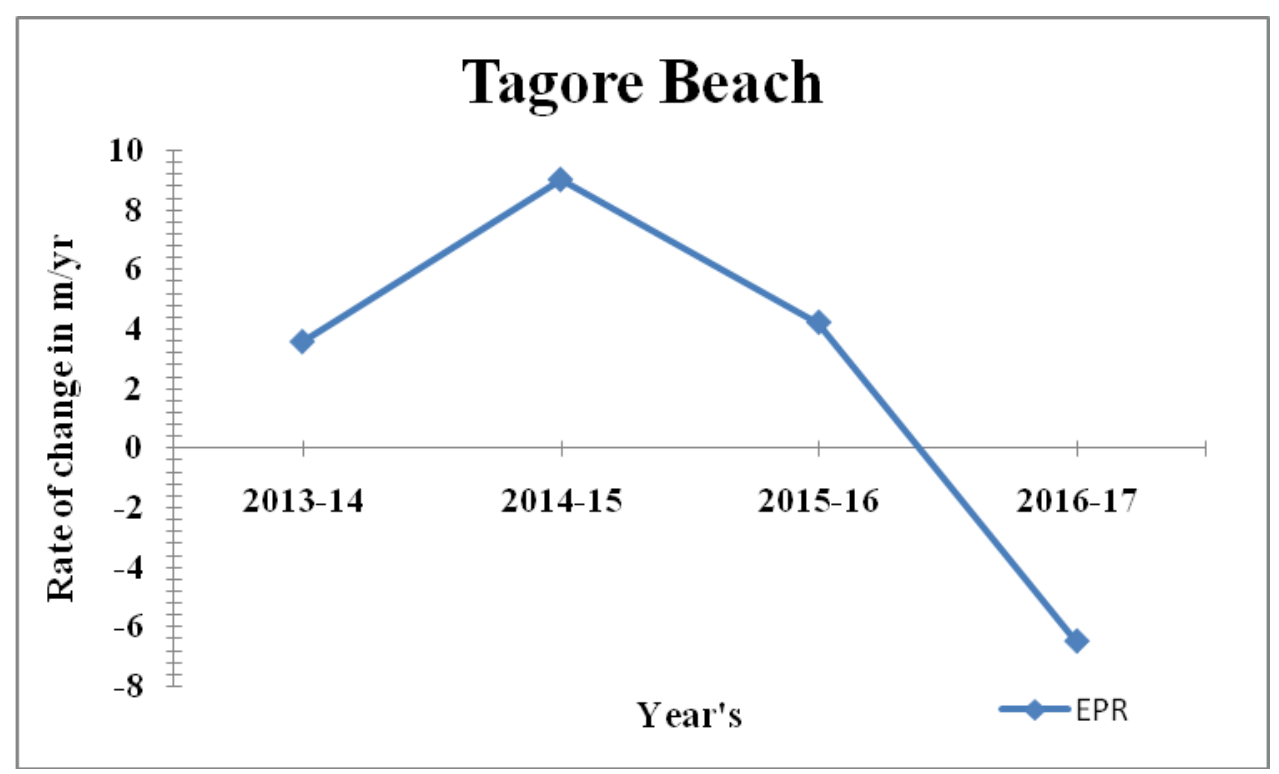

Figure 12: Shows the trend analysis of EPR for Tagore beach 


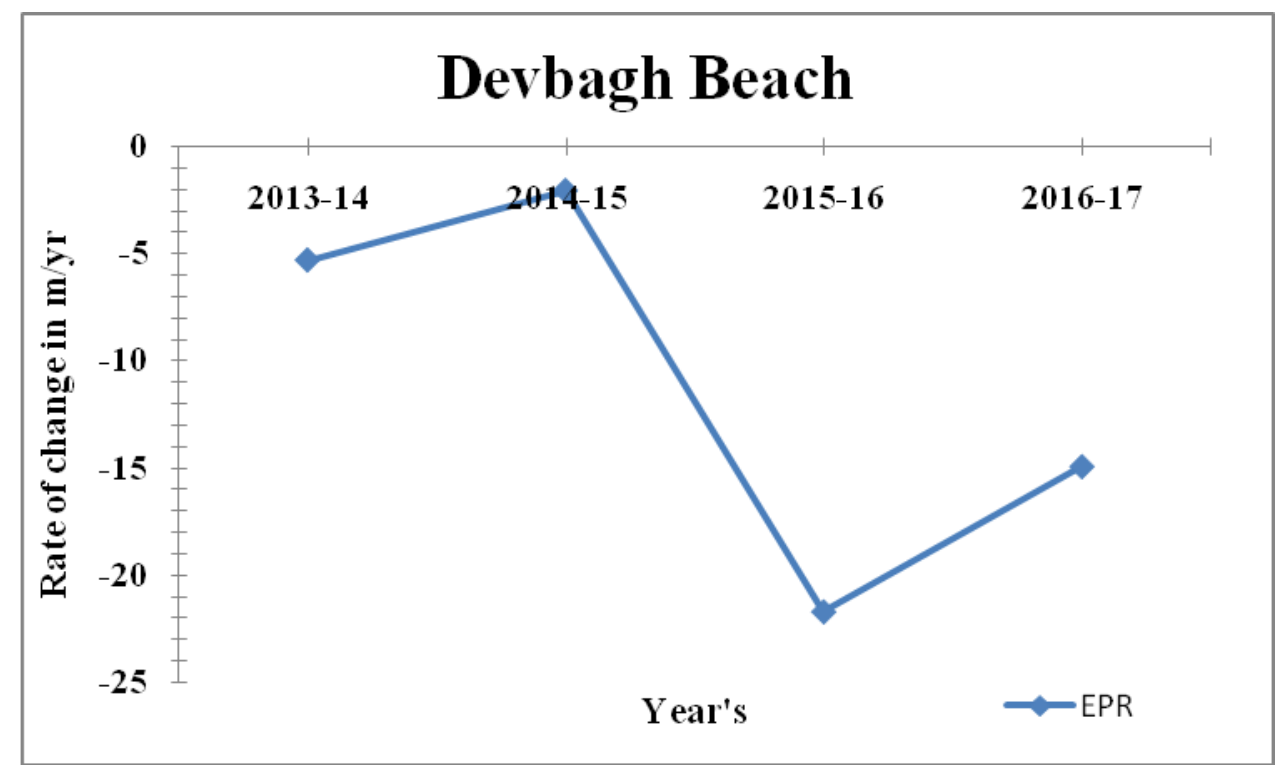

Figure 13: Shows the trend analysis of EPR for Devbagh beach

During the field visit the following photographs taken for Tagore beach and Devbagh beach. Figure 14 and 15 shows the photographs of Tagore beach and Devbagh beach respectively. In case of Devbagh beach photograph taken near to Kali estuary region and for Tagore beach little far from Kali estuary.

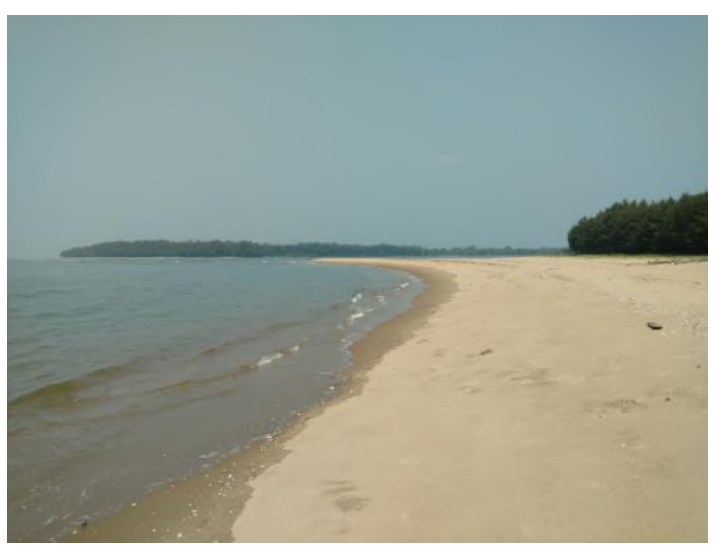

Figure 14: Shows Tagore beach

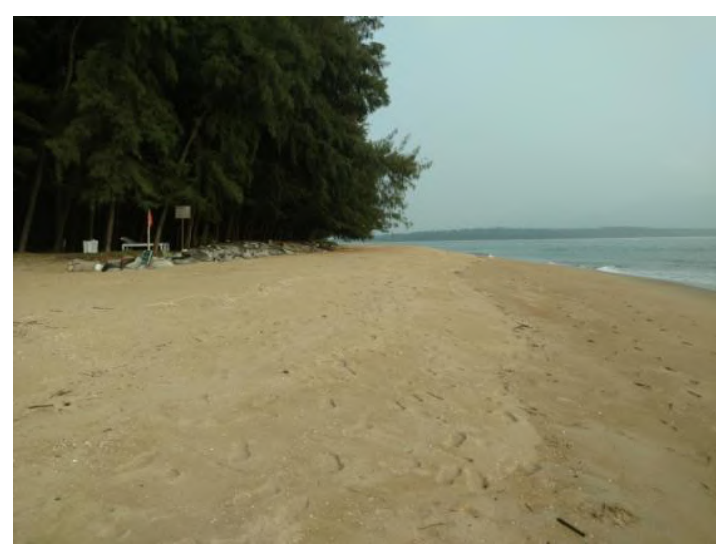

Figure 15: Shows Devbagh beach 


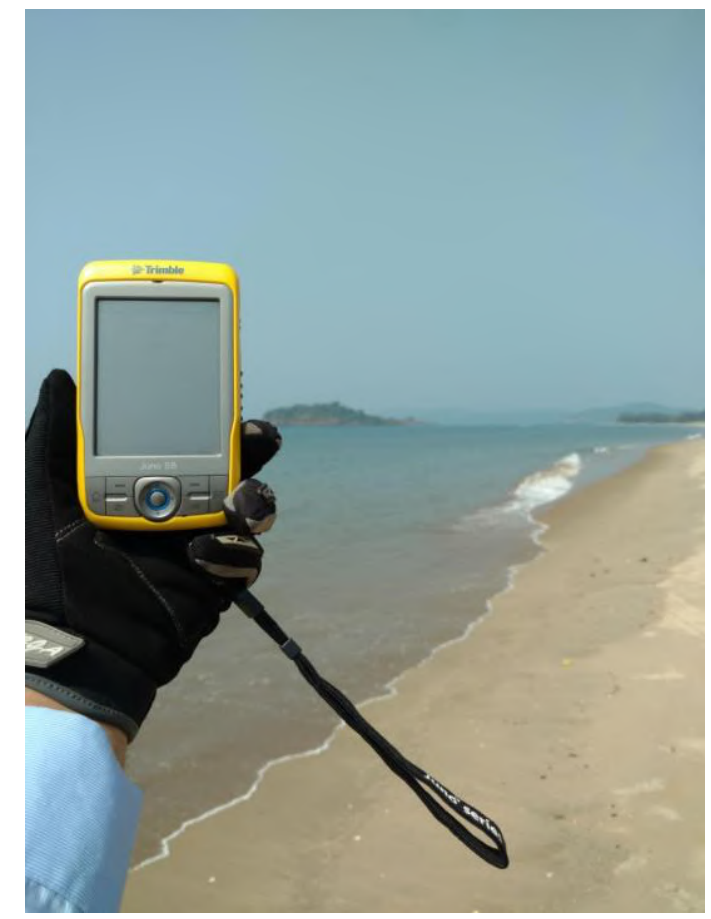

Figure 16: shows Trimble GPS which was used for Shoreline Tracking

\section{Conclusions}

Remote sensing and GIS coupled with field survey using GPS is possible to deliver a better result. For high accuracy, high-resolution satellite data may used. Rainfall factor is also responsible for shoreline change. From the study, it was found to be. The Tagore beach during the post-monsoon season with average rainfall $2916.5 \mathrm{~mm}$ for years 2013-14, average accretion rate found to be $3.56 \mathrm{~m} / \mathrm{yr}$ (EPR) and $0.11 \mathrm{~m}$ (NSM). For the years 2014-15 with average rainfall $2946.41 \mathrm{~mm}$, average accretion rate is $9.00 \mathrm{~m} / \mathrm{yr}$ (EPR) and $0.29 \mathrm{~m}$ (NSM). for 2015-16, average rainfall $2811.27 \mathrm{~mm}$, average rate is $-21.71 \mathrm{~m} / \mathrm{yr}$ (EPR) and $0.57 \mathrm{~m}$ (NSM). In case of Devbagh beach, average rainfall $2916.5 \mathrm{~mm}$ for years $2013-14$, having average rate is $-5.31 \mathrm{~m} / \mathrm{yr}$ (EPR) and $0.13 \mathrm{~m}$ (NSM). Similarly for the years 2014-15 with average rainfall $2946.41 \mathrm{~mm}$, finds average rate is $-2.07 \mathrm{~m} / \mathrm{yr}(\mathrm{EPR})$ and $0.05 \mathrm{~m}$ (NSM). For years $2015-16$ with average rainfall $2811.27 \mathrm{~mm}$, found to be average rate is $-21.71 \mathrm{~m} / \mathrm{yr}(\mathrm{EPR})$ and $0.57 \mathrm{~m}(\mathrm{NSM})$ and for years $2016-2017$, the average rate is found to be $-14.94 \mathrm{~m} / \mathrm{yr}$ (EPR) and $0.39 \mathrm{~m}$ (NSM). It is found to be, Tagore beach changed from accretion zone to erosion zone, and Devabh beach is experiencing erosion. These implies that shoreline change is threatening to Karwar coastal zone. As Landsat images are available freely, it can be useful for long-term and short-term shoreline analysis. More field observation, use of available data such as tide, wind and wave data can help to analysis further in-depth analysis. High-resolution data will boost the accuracy of shoreline analysis. The shoreline configuration details obtained from the present study will be helpful for the Stakeholders, Policy Makers, Coastal Managers, and Scientists. 


\section{References}

Addo, K.A., Jayson-Quashigah, P.N. and Kufogbe, K.S., 2011. Quantitative analysis of shoreline change using medium resolution satellite imagery in Keta, Ghana. Marine Science, 1(1), pp.1-9.

Bagli, S. and Soille, P., 2003, October. Morphological automatic extraction of Pan-European coastline from Landsat ETM+ images. In International Symposium on GIS and Computer Cartography for Coastal Zone Management (pp. 256-269).

Boak, E.H. and Turner, I.L., 2005. Shoreline definition and detection: a review. Journal of coastal research, pp.688-703.

Carter, R.W.G., 2013. Coastal environments: an introduction to the physical, ecological, and cultural systems of coastlines. Elsevier

Guariglia, A., Buonamassa, A., Losurdo, A., Saladino, R., Trivigno, M.L., Zaccagnino, A. and Colangelo, A., 2006. A multisource approach for coastline mapping and identification of shoreline changes. Annals of geophysics, 49(1).

Hegde, A.V. and Akshaya, B.J., 2015. Shoreline transformation study of Karnataka coast: geospatial approach. Aquatic Procedia, 4, pp.151-156.

Komar, P.D., 1989. Physical processes of waves and currents and the formation of placers on beach. Journal of Geology, 92, pp.637-655.

Kumar, A. and Jayappa, K.S., 2009. Long and short-term shoreline changes along Mangalore coast, India.

Kumar, V.S., Pathak, K.C., Pednekar, P., Raju, N.S.N. and Gowthaman, R., 2006. Coastal processes along the Indian coastline. Current Science, pp.530-536.

Maiti, S. and Bhattacharya, A.K., 2009. Shoreline change analysis and its application to prediction: a remote sensing and statistics based approach. Marine Geology, 257(1-4), pp.11-23.

Manca, E., Pascucci, V., Deluca, M., Cossu, A. and Andreucci, S., 2013. Shoreline evolution related to coastal development of a managed beach in Alghero, Sardinia, Italy. Ocean \& coastal management, 85, pp.6576.

Marfai, M.A., King, L., Singh, L.P., Mardiatno, D., Sartohadi, J., Hadmoko, D.S. and Dewi, A., 2008. Natural hazards in Central Java Province, Indonesia: an overview. Environmental Geology, 56(2), pp.335-351.

Mills, J.P., Buckley, S.J., Mitchell, H.L., Clarke, P.J. and Edwards, S.J., 2005. A geomatics data integration technique for coastal change monitoring. Earth Surface Processes and Landforms, 30(6), pp.651-664.

Mutaqin, B.W., 2017. Shoreline Changes Analysis In Kuwaru Coastal Area, Yogyakarta, Indonesia: An Application Of The Digital Shoreline Analysis System (dsas). International Journal of Sustainable Development and Planning, 12(7), pp.1203-1214.

Natesan, U., Parthasarathy, A., Vishnunath, R., Kumar, G.E.J. and Ferrer, V.A., 2015. Monitoring longterm shoreline changes along Tamil Nadu, India using geospatial techniques. Aquatic Procedia, 4, pp.325-332.

Pardo-Pascual, J.E., Sánchez-García, E., Almonacid-Caballer, J., Palomar-Vázquez, J.M., Priego de los Santos, E., Fernández-Sarría, A. and Balaguer-Beser, Á., 2018. Assessing the Accuracy of Automatically Extracted Shorelines on Microtidal Beaches from Landsat 7, Landsat 8 and Sentinel-2 Imagery. Remote Sensing, 10(2), p.326. 
Arunkumar Yadav, Basavanad .M. Dodamani and G.S. Dwarakish / Shoreline Change Threat .....

Pilkey, O.H. and Hume, T.M., 2001. The shoreline erosion problem: lessons from the past. Water and Atmosphere, 9(2), pp.22-23.

Scott, D.B., 2005. Coastal changes, rapid. In Encyclopedia of coastal science (pp. 253-255). Springer Netherlands.

Yang, M.D., Yang, Y.F. and Hsu, S.C., 2004. Application of remotely sensed data to the assessment of terrain factors affecting the Tsao-Ling landslide. Canadian Journal of Remote Sensing, 30(4), pp.593-603.

Zuzek, P.J., Nairn, R.B. and Thieme, S.J., 2003. Spatial and temporal considerations for calculating shoreline change rates in the Great Lakes Basin. Journal of Coastal Research, pp.125-146. 